\title{
Design of Energy Control Method for Three-Phase Buck-Type Rectifier with Very Demanding Load Steps
}

\author{
S. Zhao , J. M. Molina , M. Silva , J. A. Oliver, P. Alou, J. Torres, F. Arévalo, O. Garcia , J. A. Cobos
}

\begin{abstract}
Conventional three-phase rectifiers are controlled to achieve good power factor and low THD in the input. In the case of pulsating power loads, the fast dynamic response implies that the load pulses are reflected in the generator. These pulsating loads affect the life time operation of the generator, especially when it is not oversized (that is the case in aircraft applications). In order to smooth the power demanded from the generator, it is preferable to reduce the bandwidth of the controller to the rectifier but it affects its stability due to the fact that the right half plane pole given by the negative impedance of a constant power load requires high bandwidth control loop to compensate it. In this paper, an energy control method is proposed to employ the energy stored in the output capacitor of the rectifier to control the amount of power demanded through the rectifier. In such a way the bandwidth restriction for stability is eliminated and the bandwidth of the loop can be set slow enough to ensure smooth power demanded from the generator.
\end{abstract}

\section{INTRODUCTION}

In recent years, the increase of electrical equipment needed in More Electric Aircraft (MEA), has led to a tremendous rise in the demand of electrical power in aircraft power distribution systems [1]. Normally the power conversion system consists of two main stages: a Three-phase $\mathrm{AC} / \mathrm{DC}$ rectifier (including EMI filter) which mainly takes charge of achieving good power factor (PF) and low THD at the input; and a second stage consisting of an isolated DC/DC converter to supply the load equipment, which aims at ensuring fast dynamic response and meanwhile meeting the desirable output specifications. In this paper, the rectifier is rooted in the aircraft application with a three-phase generator supplying phase-to-neutral voltage of $115 \mathrm{~V}$ RMS, $400 \mathrm{~Hz}$. The nominal output power of the rectifier is $\mathrm{P}_{\text {loadnom }}=13 \mathrm{~kW}$ with $\mathrm{V}_{\mathrm{o}, \mathrm{nom}}=200 \mathrm{~V}$. The output of the rectifier is an isolated DC/DC Full-Bridge supplying the load equipment. The input of the full-bridge is rated between $150 \mathrm{~V}$ DC and $250 \mathrm{~V}$ DC. As a result, the buck-type rectifier is preferred over boost-type rectifier in this application because it can provide a wide output voltage range down to low voltages maintaining good power factor at the input. Furthermore, the advanced modulation method for the buck-

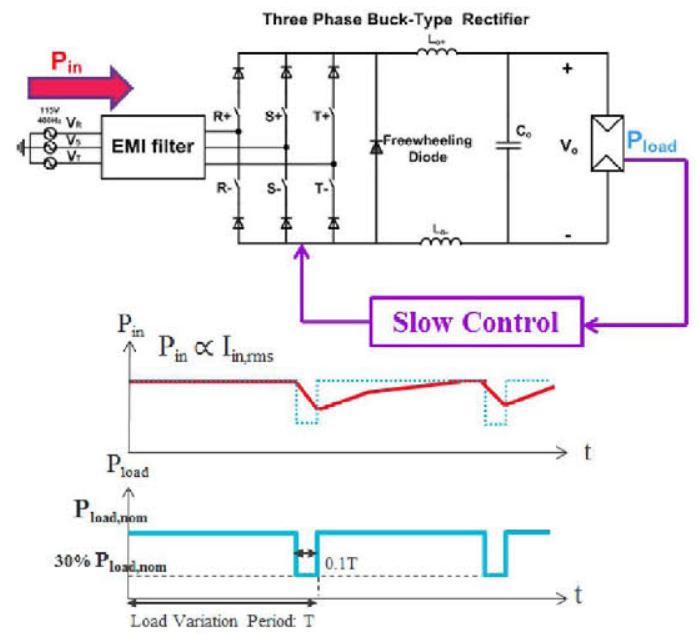

Figure 1: Schematic of the proposed slow-bandwidth control loop.

type rectifier discussed in [2] and [3] is contributing because of its advantageous rms value [4], [5] in the ripple components. In the conventional control method discussed in [6], an inner DC inductor current loop and an outer output voltage loop [7] is implemented based on a resistive load; whereas in this application the rectifier is loaded with a DC/DC converter operating as a constant power source at steady state, which imposes more restrictions in the control design. Notably in this application, the DC/DC Full-Bridge with its load device presents a periodically dynamic power profile (see $\mathrm{P}_{\text {load }}$ in Fig. 1). For the sake of enlarging the life span of the aircraft generator under these high power steps, an energy control method is proposed to control the rectifier in low bandwidth in order to demand smooth power from the generator while abrupt load steps happen (see $\mathrm{P}_{\text {in }}$ in Fig. 1). Meanwhile, by the proposed method, the constraint of the right half plane pole brought by the constant power load is eliminated. Therefore the control bandwidth can be configured low enough to protect the generator. This slow energy control method penalizes the output capacitance, because the power unbalance happed at the transient can only be handled by the output capacitance. 


\section{SyStem MODELING With CONVENTIONAL OUTER VOLTAGE CONTROL LOOP}

As stated above, the aim of the proposed method is to control the rectifier to demand smooth power from the generator while a load step occurs. It implies that the control loop should be slow enough, that the abrupt load step does not provoke the rectifier to react immediately.

Starting from the conventional modeling approach for the three-phase buck-type rectifier [6], it is generally considered as a controlled current source $\left(I_{g}\right.$ in Fig. 2$)$ which denotes the $\mathrm{DC}$ inductor current in the output filter and can be controlled through an inner fast DC inductor current loop (neglected in Fig. 2). Moreover, an outer slower voltage control loop (shown in Fig. 2) is usually implemented. Thus, in this case at steady state, the plant model of the rectifier in Fig. 2 can be described as

$$
C_{o} \frac{d v_{o}(t)}{d t}=i_{g}(t)-\frac{p_{\text {load }}(t)}{v_{o}(t)}
$$

At a certain operating point, the small-signal open-loop transfer function of $\mathrm{v}_{\mathrm{d}} / \mathrm{i}_{\mathrm{g}}$ can be derived as

$$
\frac{\tilde{v}_{o}(s)}{\tilde{\imath}_{g}(s)}=\frac{-R_{\text {nom }}}{1-R_{\text {nom }} C_{0} \cdot s}
$$

where $R_{\text {nom }}=\frac{V_{o, n o m}^{2}}{P_{o, n o m}}$. Obviously, the negative equivalent load resistance in the denominator of (2) implies a right half plane pole in the open loop transfer function which is open-loop unstable. In order to ensure stability, according to Nyquist Stability Criterion [8], it is necessary to implement a controller with a loop gain big enough to make the contour encircle point $(-1, j 0)$ counterclockwise in the Nyquist plot [9]. Accordingly, this feature prevents the control loop from going even slower since the loop bandwidth is constrained by $B W>\frac{2}{2 \pi R_{\min } C_{o}}$ $\left(\mathrm{R}_{\min }\right.$ implies value of the minimum equivalent load resistance at maximum power).

\section{System Modeling AND ENERGy CONTROL Method}

Since the whole rectifier system is rated for $13 \mathrm{~kW}$, after the comparison of different rectifier system architectures and EMI filter structures, the distributed rectifier architecture of 7 rectifiers in parallel and each rated for $2 \mathrm{~kW}$ with its own EMI filter stands out. Thus, section III.A introduces a slow outer energy control loop targeting on controlling the power injected through the rectifier with the energy stored in the capacitor. This design is done for the whole rectifier system of $13 \mathrm{~kW}$. Thereafter, section III.B and III.C are done dedicated to each rectifier cell of $2 \mathrm{~kW}$ with output capacitance scaled

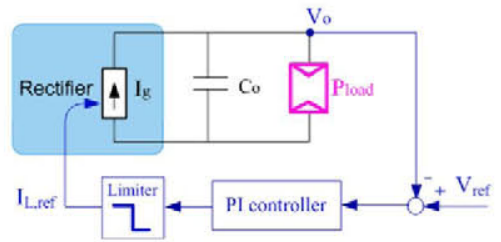

Figure 2: Simplified model of a current controlled buck rectifier with conventional outer voltage loop. down from the one of the whole $13 \mathrm{~kW}$ ). In section III.B, a fast inner DC current loop controlled by the reference $\mathrm{I}_{\mathrm{g}}$ (equal to $P_{\text {inj }} / V_{o}$ ) which implies the desired average current of the inductor is discussed. In the end, section III.C discusses an over-voltage protection scheme. While $\mathrm{V}_{\mathrm{o}}$ tends to go out of its upper limit, the protection scheme aims at quickly adjusting injected power to the same value as instantaneous load power in order to prevent $\mathrm{V}_{\mathrm{o}}$ from further increasing.

Multiplying $\mathrm{v}_{\mathrm{o}}(\mathrm{t})$ to both sides of (1), there is:

$$
v_{o}(t) C_{o} \frac{d v_{o}(t)}{d t}=v_{o}(t) i_{g}(t)-p_{\text {load }}(t)
$$

Assuming that $\mathrm{C}_{\mathrm{o}}$ is ideal, the left part of (3) happens to be the derivative of real-time energy stored in $\mathrm{C}_{\mathrm{o}}$ over time [10].

Thus, we have

$$
\frac{d \varepsilon_{c}(t)}{d t}=p_{\text {inj }}(t)-p_{\text {load }}(t)
$$

It is straight-forward to obtain the small-signal transfer function of $\varepsilon_{\mathrm{c}} / \mathrm{p}_{\mathrm{inj}}$ as

$$
\frac{\tilde{\varepsilon}_{c}(s)}{\tilde{p}_{\text {inj }}(s)}=\frac{1}{s}
$$

For this plant model as simple as an integrator, the bandwidth can be configured low enough without being concerned about stability issues. Thus, it is proposed to control the rectifier as a power source $\left(\mathrm{P}_{\mathrm{inj}}\right)$ using the energy stored in the capacitance $\left(\mathrm{E}_{\mathrm{c}}=0.5 \mathrm{C}_{\mathrm{o}} V_{\mathrm{o}}^{2}\right)$ instead of the $\mathrm{DC}$ bus voltage $\left(\mathrm{V}_{\mathrm{o}}\right)$.

\section{A. Outer Energy Control Loop}

Based on the plant model in (5), a PI controller for the outer capacitor energy loop can be implemented as shown in the block diagram in Fig. 3. By adjusting the gains of the PI controller, different control bandwidths can be reached without restriction on stability issues.

As can be seen, the output capacitance $\mathrm{C}_{\mathrm{o}}$ is a crucial component in the rectifier system. Especially under the condition of a low-bandwidth control, while a load step happens, the power unbalance between the abrupt load drop and the smoothly varied input power demanded from the generator can only be handled by the output capacitor $\mathrm{C}_{\mathrm{o}}$. This naturally results in a variation of $\mathrm{V}_{\mathrm{o}}$. While deciding the bandwidth value, the optimal $\mathrm{C}_{\circ}$ value also has to be concerned, since volume and weight are strict requirements in aircraft applications. Fig. 4 shows the relationship between the input power variation $\left(\Delta \mathrm{P}_{\text {in }}\right)$ from the nominal power and the $\mathrm{C}_{\mathrm{o}}$ value needed in order to control $\mathrm{V}_{\mathrm{o}}$ varies right inside nominal $200 \mathrm{~V}$ up to $300 \mathrm{~V}$ (ideally) while a load step happens.

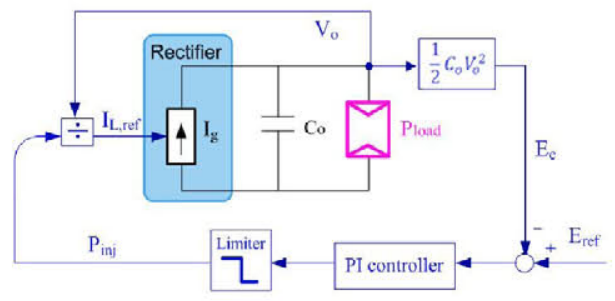

Figure 3: Simplified model of the proposed outer energy control loop. 
Obviously, there is a trade-off between $\Delta \mathrm{P}_{\text {in }}, \mathrm{C}_{\mathrm{o}}$ and $\Delta \mathrm{V}_{\mathrm{o}}$. This is because slower control loop (i.e. smaller $\Delta \mathrm{P}_{\text {in }}$ ) brings bigger $\mathrm{P}_{\mathrm{in}}-\mathrm{P}_{\text {out }}$ unbalance during transients, which requires bigger $\mathrm{C}_{\mathrm{o}}$ value to handle, meanwhile keeping $V_{o}$ inside the nominal range. Based on Fig. 4 , the point with $\mathrm{C}_{\mathrm{o}}=34 \mathrm{mF}, \Delta \mathrm{P}_{\text {in }}=1.8 \mathrm{~kW}$ is chosen to demonstrate the design. Thus, with the loop gain shown in Fig. 5, a PI controller for outer energy loop with a bandwidth of $0.16 \mathrm{~Hz}$ is designed to meet the desired $\Delta \mathrm{P}_{\text {in }}$ value. The transient response of the averaged model simulation is shown in Fig. 6, where an input phase RMS current variation $\Delta \mathrm{I}_{\text {in,rms }}=4.5 \mathrm{~A}$ (only $12 \%$ of nominal input phase RMS current) is obtained.

Considering the same $\mathrm{C}_{\mathrm{o}}=34 \mathrm{mF}$ and the same operating point, in contrast with the proposed energy control method, the conventional outer voltage control is constrained by the stability criterion: $B W>\frac{2}{2 \pi R_{\min } C_{o}}=3 \mathrm{~Hz}$. The transient response

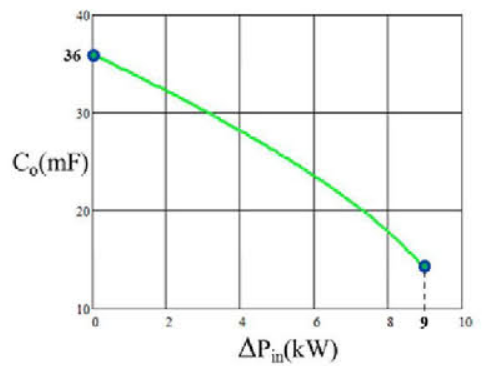

Figure 4: Relationship of Co with respect of different $\Delta \mathrm{P}_{\text {in }}$ for $\mathrm{V}_{\mathrm{o}}$ variation from $200 \mathrm{~V}$ to $300 \mathrm{~V}$.

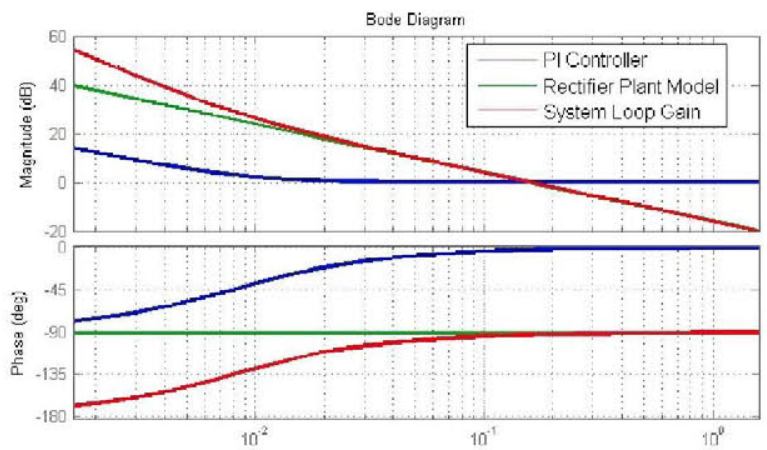

Figure 5: Bode diagram of the system with energy control loop at bandwidth of $0.16 \mathrm{~Hz}$.

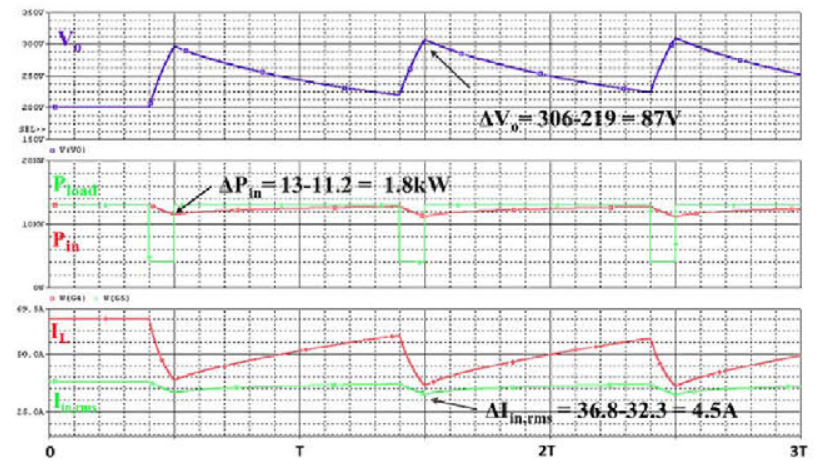

Figure 6: Transient response of the proposed control at bandwidth of $0.16 \mathrm{~Hz}$. of the averaged model merely at the boundary of the stability constriction is shown in Fig. 7, where a bigger input phase RMS current variation $\Delta \mathrm{I}_{\text {in,rms }}=16.8 \mathrm{~A}$ ( $46 \%$ of the nominal input phase RMS current) happens.

\section{B. Inner DC Current Loop}

With the method stated above, according to (4) the outer energy control loop is able to adjust $\mathrm{P}_{\text {inj }}$ equivalent to $\mathrm{P}_{\text {load }}$ at steady state by controlling $\mathrm{E}_{\mathrm{c}}$ (relating to $\mathrm{V}_{\mathrm{o}}$ ). Thus, for the inner inductor current loop design, the load can be considered as an equivalent positive resistive load: $R_{\text {nom }}=\frac{V_{o, \text { nom }}^{2}}{P_{\text {o,nom }}}$. Then, the plant transfer function for the inductor current $\left(\mathrm{i}_{\mathrm{L}}\right)$ versus the modulation index (m) [11] is equal to

$$
G_{\tilde{L}_{L} / \tilde{m}}(s)=\frac{R_{\text {nom }} C_{0} U_{N, e q} \cdot s+U_{N, e q}}{R_{\text {nom }} C_{o} L_{o} \cdot s^{2}+L_{o} \cdot s+R_{\text {nom }}}
$$

where $\mathrm{U}_{\mathrm{N}, \mathrm{eq}}$ refers to the equivalent $\mathrm{DC}$ input voltage [7] with the relationship of $U_{N, e q}=\frac{3}{2} \widehat{U}_{N}=244 \mathrm{~V}$, and $\mathrm{L}_{\mathrm{o}}=\mathrm{L}_{\mathrm{o}+}+\mathrm{L}_{\mathrm{o}}$ $=150 \mathrm{uH}$. According to this plant model, a PI controller is adopted in the inner inductor current control loop and the Bode diagram is shown in Fig. 8 with a bandwidth of $4.2 \mathrm{kHz}$.

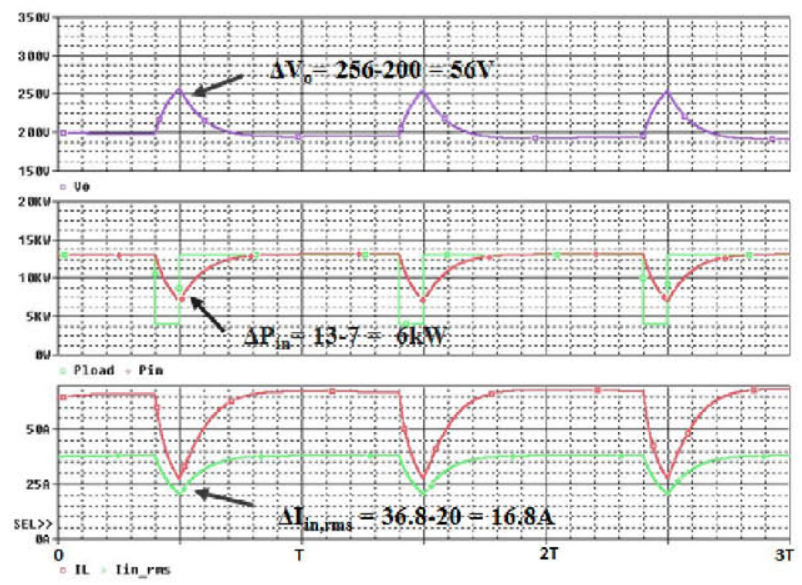

Figure 7: Transient response of the conventional outer voltage loop at stability boundary with bandwidth of $3 \mathrm{~Hz}$.

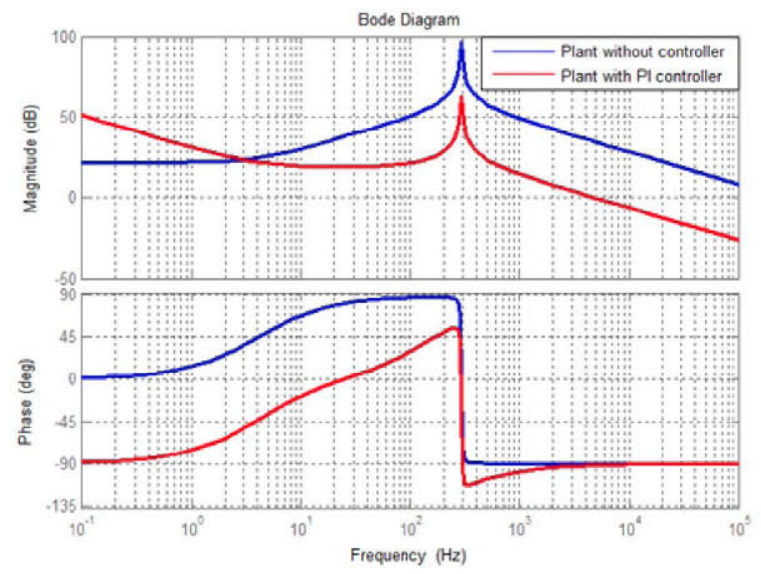

Figure 8: Open-loop Bode diagram of the inner DC current loop without controller and with the designed PI controller. 


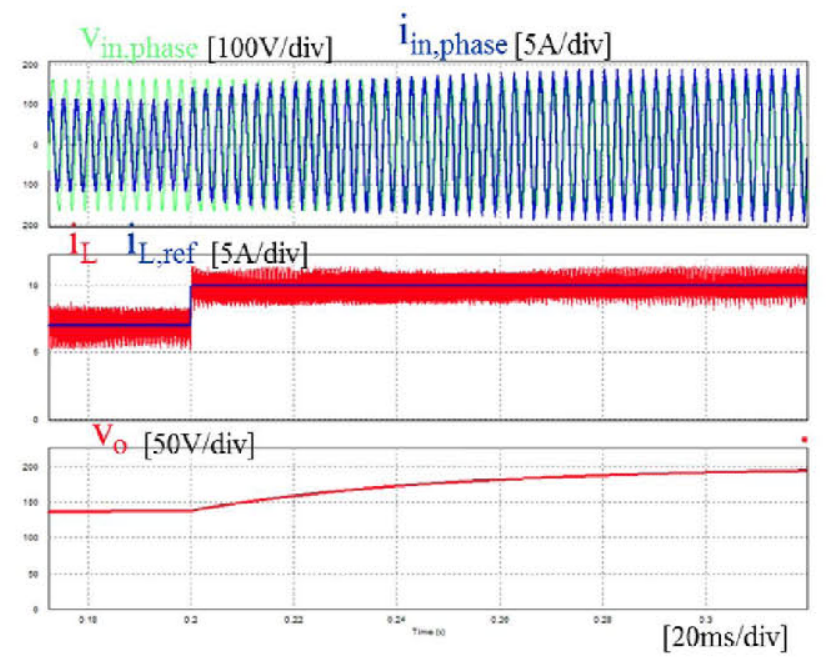

Figure 9: Step reference tracking response of the inner DC current loop with the designed PI controller.

Then by the switching model simulation, a step reference response for the average inductor current from $7 \mathrm{~A}$ to $10 \mathrm{~A}$ is captured in Fig. 9, consequently $\mathrm{V}_{\mathrm{o}}$ varies from $140 \mathrm{~V}$ to the new steady state of $200 \mathrm{~V}$. The graph shows that designed inner DC current controller is able to track the reference for average inductor current immediately.

\section{Over-voltage Protection Scheme}

In reality, for this unidirectional buck-type rectifier, when $\mathrm{V}_{\mathrm{o}}$ is higher than $244 \mathrm{~V}$ (according to $V_{o}=M \cdot 1.5 \widehat{U}_{N, e q}$ where $M=1$ ), the rectifier cannot work properly to deliver current to the load. Thus, an over-voltage protection scheme is designed to ensure faster outer energy loop control when $V_{0}$ tends to go over $235 \mathrm{~V}$ (set as the upper limit for $\mathrm{V}_{\mathrm{o}}$ in this case) during the dynamic load step; while $V_{o}$ stays inside the nominal range, the designed $0.16 \mathrm{~Hz}$ small-bandwidth loop takes effect.

Fig. 10 shows the switching model simulation of the $2 \mathrm{~kW}$ rectifier cell with the proposed over-voltage protection scheme implemented. It can be seen that, when load step happens, the outer energy control loop is working in small-bandwidth which controls $P_{\text {in }}$ to respond smoothly; once $V_{o}$ tends to exceed $235 \mathrm{~V}$, the high-bandwidth energy loop is implemented which makes $P_{\text {in }}$ react fast to $P_{\text {load }}$ and thereby clamps $V_{\text {o }}$ inside the regulation band. Accordingly, $I_{\text {in,phase }}$ is varying

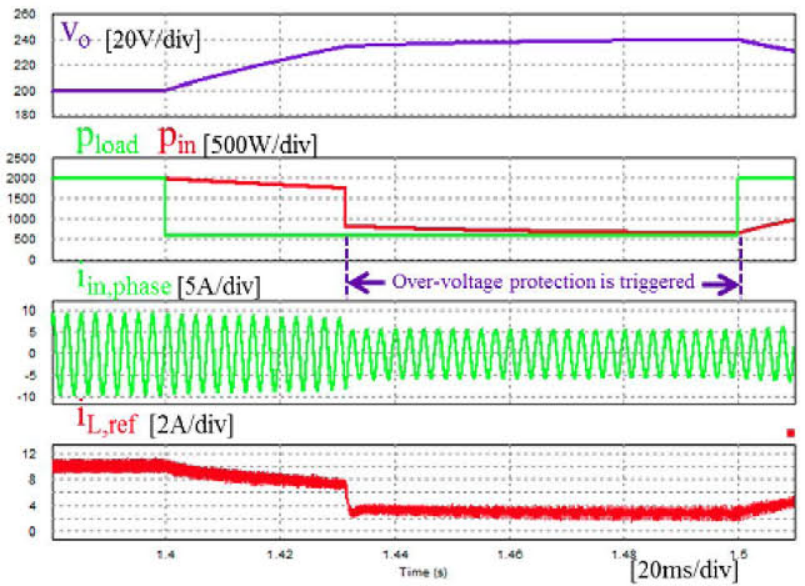

Figure 10: Transient response for switching model simulation applying over-voltage protection.

smoothly while a load step occurs and after entering the protection mode, it changes fast to demand the balance between $\mathrm{P}_{\text {in }}$ and $\mathrm{P}_{\text {load }}$.

\section{EXPERIMENTAL RESULTS}

A $2 \mathrm{~kW}$ prototype of the three-phase buck-type PWM rectifier including EMI filter [12], [13] has been built. For this aircraft application, the EMI standard to comply with is MILSTD-461E [14]. Also the proposed energy control method has been implemented as shown in Fig. 11. Digital control is employed with a TI TMS320C28346 DSP experimenter's kit [15] and a TI ADS8556 ADC evaluation module [16].

As stated above, the slow bandwidth control loop penalizes the output capacitance. That is to say, for a fixed $V_{o}$ variation range, the bigger the capacitance, the slower the bandwidth can reach. In order to minimize volume and weight in aircraft applications, considering the state-of-the art, electrolytic capacitors always show the best energy density and applicable quantities over other technologies (e.g. ceramic, film, etc.). However in aircraft applications, component reliability is also an extremely important factor. Since electrolytic capacitors have the undesirable reliability as well as poor tolerance, film capacitors stand out as a good combination of better energy density, applicable quantities and preferable reliability. Also for the sake of availability, in the $2 \mathrm{~kW}$ rectifier prototype two film capacitors from EPCOS B25620B1118K103 [15]

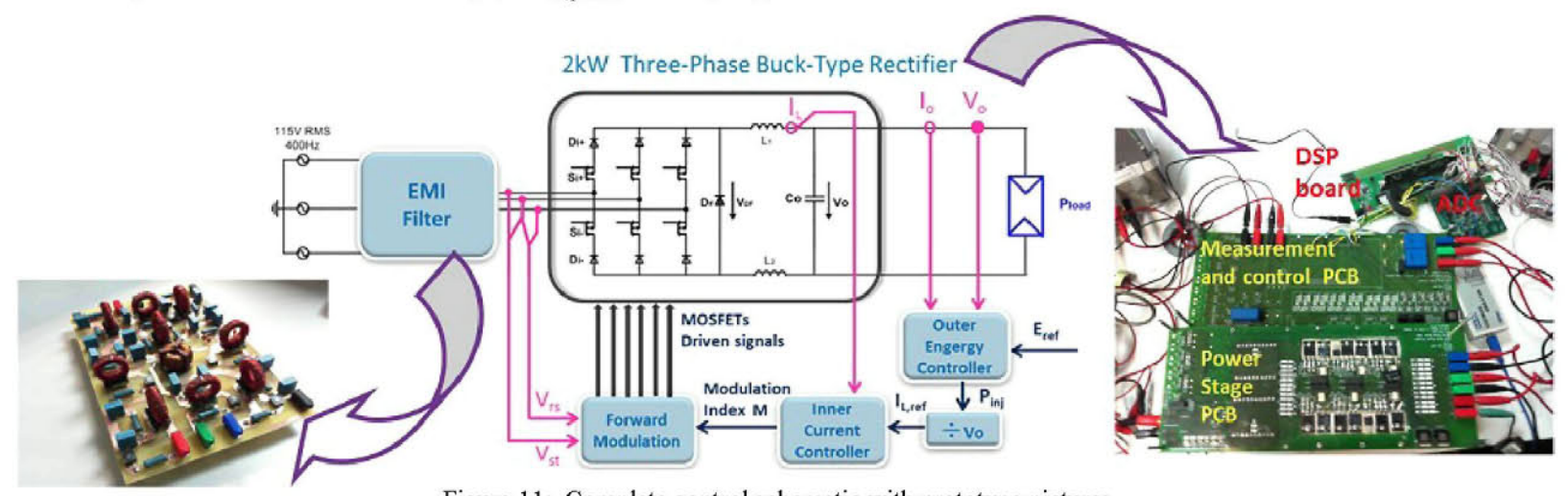

Figure 11: Complete control schematic with prototype pictures. 


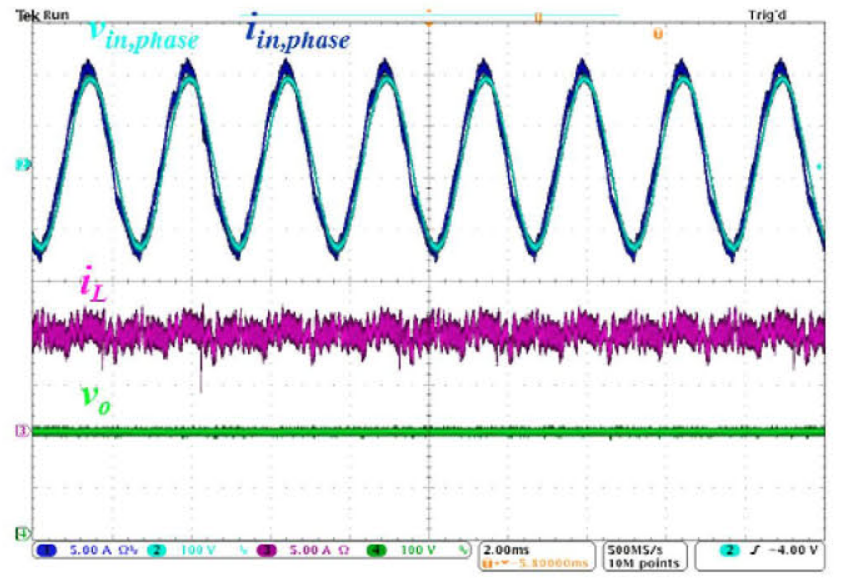

Figure 12: Open loop measurement of the rectifier system at $2 \mathrm{~kW}$, with load resistor of $20 \Omega$.

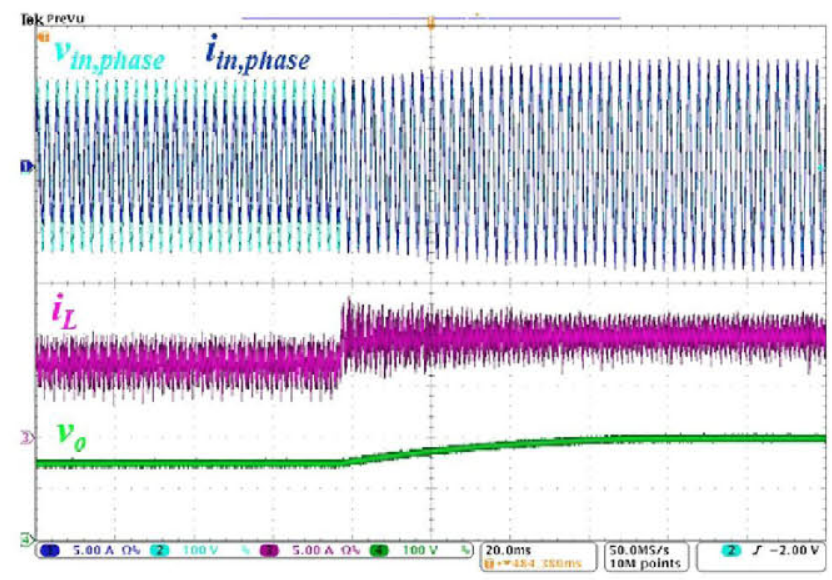

Figure 13: Inner DC current loop step reference tracking from 7A to $10 \mathrm{~A}$ with load resistor of $20 \Omega$.

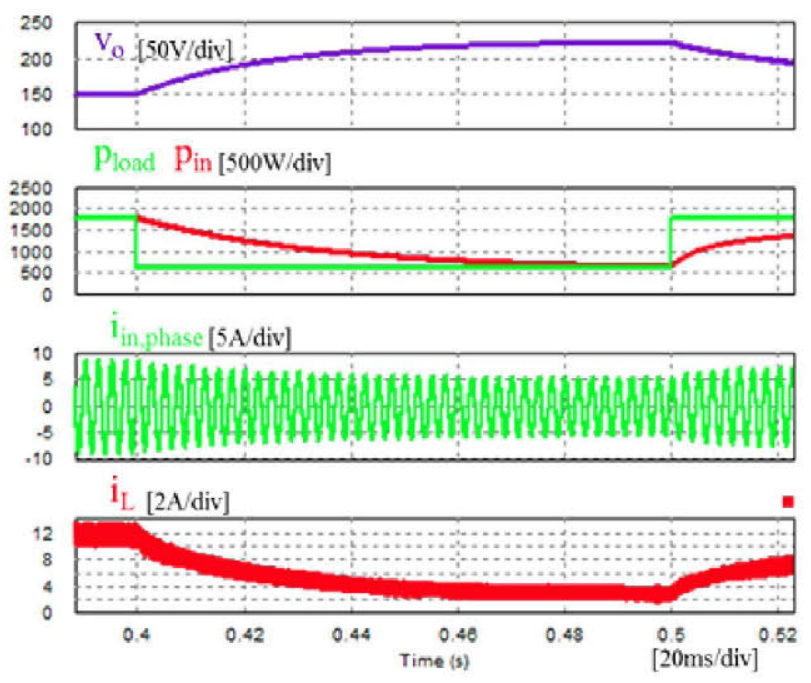

Figure 14: Transient response of load step from $1.8 \mathrm{~kW}$ down to $650 \mathrm{~W}$, with bandwidth of $3.98 \mathrm{~Hz}$ and consequently causes $\mathrm{V}_{0}$ to increase slowly from $150 \mathrm{~V}$ to $220 \mathrm{~V}$.

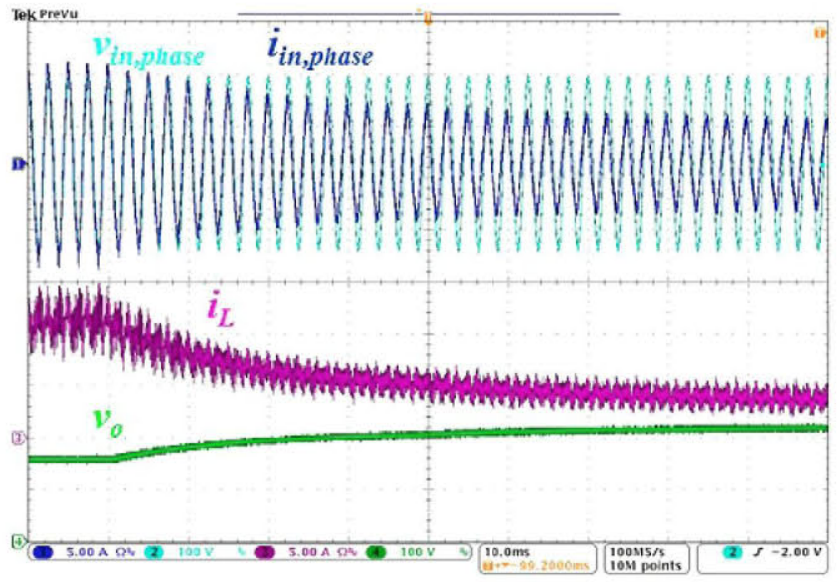

Figure 15: Energy loop working under load step from $1.8 \mathrm{~kW}$ down to $650 \mathrm{~W}, \mathrm{I}_{\mathrm{in}}$ is controlled to vary smoothly and consequently causes $\mathrm{V}_{\mathrm{o}}$ to increase slowly from $150 \mathrm{~V}$ to $220 \mathrm{~V}$.

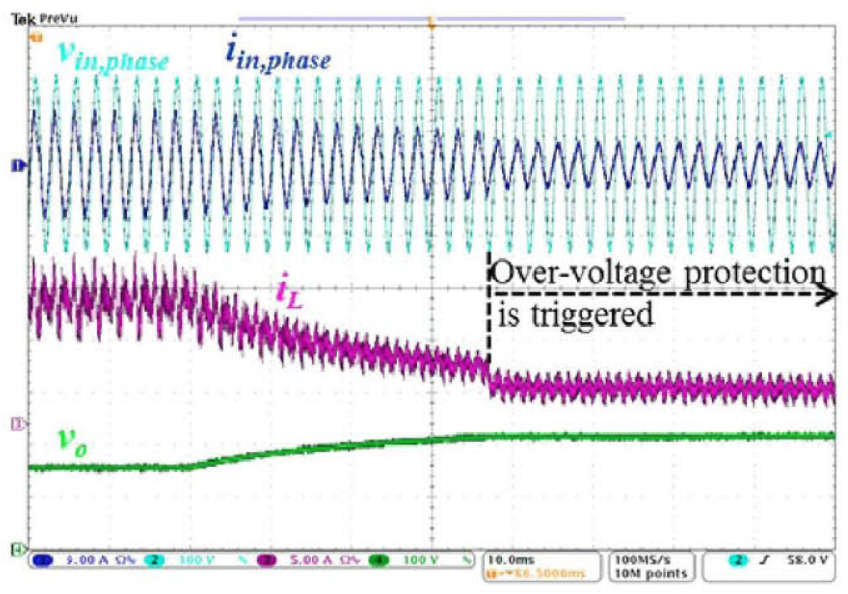

Figure 16: Over-voltage protection scheme is triggered when $\mathrm{V}_{0}$ is beyond $215 \mathrm{~V}$ during the load step, meanwhile energy loop bandwidth is changed into a bigger value in order to control $P_{\text {in }}$ quickly converged to $P_{\text {load. }}$.

(each of $1.1 \mathrm{mF}$, with volume of $2.4 \mathrm{~L}$ ) are installed in the output of the rectifier prototype. All the experimental results are done with $\mathrm{C}_{\mathrm{o}}=2.2 \mathrm{mF}$.

Fig. 12 presents the open loop measurement of the rectifier operating at maximum output power of $2 \mathrm{~kW}$ with $\mathrm{V}_{\mathrm{o}}=200 \mathrm{~V}$ (fixed modulation index of 0.82) and load resistor of $20 \Omega$. The THD is $6 \%$ and PF is 0.98 (measured with Yokogawa WT1800 Power Analyzer [18]), and the overall efficiency is $95 \%$. It fully complies with our system specification of THD $10 \%$, PF 0.95 and efficiency of $95 \%$. The THD can also be improved, because the current distortion shown at the input current as well as the inductor current comes from the moment when two line voltages are intersecting at the same value. A Phase Lock Loop (PLL) can help to decide the intersecting point more accurately.

As to the inner DC current loop, Fig. 13 presents a 7A to $10 \mathrm{~A}$ step reference response on the load resistor of $20 \Omega$. It can be seen that the experimental results match the switching 
model simulation, i.e., inductor current is able to track the step reference quickly.

Since the output capacitance of $2.2 \mathrm{mF}$ is adopted in the $2 \mathrm{~kW}$ prototype, a test configuration of a sudden $\mathrm{P}_{\text {load }}$ step from $1.8 \mathrm{~kW}(150 \mathrm{~V})$ to $650 \mathrm{~W}$ and then lasting for $100 \mathrm{~ms}$ is chosen. The bandwidth is configured at $3.98 \mathrm{~Hz}$ at the moment due to an inadequate $\mathrm{C}_{\mathrm{o}}=2.2 \mathrm{mF}$ (compared to the demonstrated $0.16 \mathrm{~Hz}$ bandwidth with $5.2 \mathrm{mF}$ for $2 \mathrm{~kW}$ ). The switching model simulation of this configuration is captured in Fig. 14. Experimental results in Fig. 15 verify the energy loop working under an electric load (Chroma DC Electric Load 63204 [19]) of constant power mode for a sudden load step from $1.8 \mathrm{~kW}$ to $650 \mathrm{~W}$. It can be seen that after the load step happens, the rms value of $i_{\text {in,phase }}$ is decreasing slowly which also suggests the input power is reducing smoothly and finally after a time interval of $90 \mathrm{~ms}, \mathrm{~V}_{\mathrm{o}}$ varies from $150 \mathrm{~V}$ to the new steady state of $220 \mathrm{~V}$. Thereafter, $P_{\text {in }}$ is equivalent with $P_{\text {load }}$ which maintains the balance on the $\mathrm{E}_{\mathrm{c}}$ (also referring to $\mathrm{V}_{\mathrm{o}}$ ). Besides, the average value of $i_{L}$ is decreasing, which is controlled by the desired $\mathrm{P}_{\text {inj }}$ divided by $\mathrm{V}_{\mathrm{o}}$.

According to the over-voltage protection scheme designed in section III.C, an experimental result is shown in Fig. 16. The limit to trigger the protection scheme is configured as $215 \mathrm{~V}$ in this experiment. It is obvious that once $V_{o}$ varies over the $215 \mathrm{~V}$ boundary, the bandwidth of the energy control loop is changed to a higher value and therefore $V_{o}$ is kept constant while $\mathrm{P}_{\text {in }}$ quickly converges to $\mathrm{P}_{\text {load }}$. Consequently a new steady state of $i_{\text {in,phase }}$ and $i_{L}$ is maintained thereafter.

\section{CONCLUSIONS}

For the sake of protecting the life span of the aircraft generator, while a power load step happens, a smoothly controlled input power is intended in this paper. This smoothly varied input power ensures a slowly varied input current instead of an abruptly changed one, which is greatly beneficial to the aircraft generator. Furthermore, this proposed slow bandwidth control penalizes on the value of output capacitance since during the transients, the power unbalance between smoothly varied input power and the abruptly changed load power is handled by the capacitance.

With the conventional control approach of an inner DC current loop with an outer voltage loop, in the case of a bucktype rectifier with a constant power load, the right half plane pole introduced by the characteristic of the constant power load brings the lowest control bandwidth limitation (i.e. $3 \mathrm{~Hz}$ analyzed in section III.A) concerning stability issues. The proposed energy control method is able to eliminate this restriction because the considered control plant is: the energy in the capacitor $\left(E_{c}\right)$ over the injected power through the rectifier $\left(\mathrm{P}_{\text {inj }}\right)$. This plant model is as simple as an integrator. Thus the energy control loop bandwidth can be chosen free from the stability constraint. As a result, an energy control loop of $0.16 \mathrm{~Hz}$ bandwidth (18 times smaller than $3 \mathrm{~Hz}$, also analyzed in section III.A) is designed and verified at simulation level. For the experimental result, the energy control loop with over-voltage protection is validated on a $2 \mathrm{~kW}$ rectifier prototype at bandwidth of $3.98 \mathrm{~Hz}$, with an output capacitance of $2.2 \mathrm{mF}$.

\section{REFERENCES}

[1] S. Chandrasekaran, D. K. Lindner, D. Boroyevich, "Analysis of subsystem integration in aircraft power distribution systems," Circuits and Systems, 1999. ISCAS '99. Proceedings of the 1999 IEEE International Symposium on, vol. 5, pp. 82-85, 1999.

[2] T. Nussbaumer, and J. W. Kolar, "Advanced modulation scheme for three-phase three-switch buck-type PWM rectifier preventing mains current distortion originating from sliding input filter capacitor voltage intersections." Power Electronics Specialist Conference, 2003. PESC'03. 2003 IEEE 34th Annual, vol. 3, pp. 1086-1091. IEEE, 2003.

[3] T. Nussbaumer, and J. W. Kolar, "Improving mains current quality for three-phase three-switch buck-type PWM rectifiers." Power Electronics, IEEE Transactions on, vol. 21, no. 4, pp. 4967-973, Jul. 2006.

[4] M. Baumann, T. Nussbaumer, J.W. Kolar, "Comparative evaluation of modulation methods of a three-phase buck + boost PWM rectifier. Part I: Theoretical analysis," Power Electronics, IET, vol. 1, no. 2, pp. 255, 267, Jun. 2008.

[5] M. Baumann, T. Nussbaumer, J.W. Kolar, "Comparative evaluation of modulation methods of a three-phase buck + boost PWM rectifier. Part II: Experimental verification," Power Electronics, IET, vol. 1, no. 2, pp. 268274, Jun. 2008.

[6] T. Nussbaumer, G. Gong, M.L. Heldwein, J.W. Kolar, "Controloriented modeling and robust control of a three-phase buck+boost PWM rectifier (VRX-4)," Industry Applications Conference, 2005. Fourtieth IAS Annual Meeting. Conference Record of the 2005, vol. 1, pp. 169-176, Oct. 2005.

[7] T. Nussbaumer and J.W. Kolar, "Comparative evaluation of control techniques for a three-phase three-switch buck-type AC-to-DC PWM converter system," Nordic Workshop on Power and Industrial Electronics (NORPIE '02), Aug. 2002.

[8] R. C. Dorf, R. H. Bishop, Modern Control Systems, $12^{\text {th }}$ edition, Pearson, 2010.

[9] J. S. Freudenberg, D. Looze, "Right half plane poles and zeros and design tradeoffs in feedback systems," Automatic Control, IEEE Transactions on, vol.30, no.6, pp.555,565, Jun. 1985.

[10] A. Stupar, T. Friedli, J. Miniböck, M. Schweizer, and J.W. Kolar, "Towards a 99\% efficient three-phase buck-type PFC rectifier for $400 \mathrm{~V} \mathrm{DC}$ distribution systems," Power Electronics, IEEE Transactions on, vol. 27, no. 4, pp. 1732-1744, Apr. 2012.

[11] J. Doval-Gandoy, and C. M. Penalver. "Dynamic and steady state analysis of a three phase buck rectifier." Power Electronics, IEEE Transactions on, vol. 15, no. 6, pp. 953-959, Nov. 2000.

[12] T. Nussbaumer, M. Baumann, and J. W. Kolar. "Comprehensive design of a three-phase three-switch buck-type PWM rectifier." Power Electronics, IEEE Transactions on, vol. 22, no. 2, pp. 551-562, Mar. 2007.

[13] M. Silva, N. Hensgens, J. Oliver, P. Alou, O. Garcia, J.A. Cobos, "New considerations in the input filter design of a three-phase buck-type PWM rectifier for aircraft applications," Energy Conversion Congress and Exposition (ECCE), 2011 IEFE, pp. 4087-4092, Sept. 2011.

[14] MIL-STD-461E, Requirements for the control of electromagnetic interference characteristics of subsystems and equipment Std., August 1999.

[15] http://www.ti.com/product/tms320c28346

[16] http://www.ti.com/tool/ADS8556EVM

[17] http://www.epcos.com

[18] http://tmi.yokogawa.com

[19] http://www.chromausa.com/dcloads.php 